\title{
O processo inclusivo do surdo e deficiente auditivo: uma busca na revisão
}

\section{The inclusive process of the deaf and hearing impaired: a search in the review \\ El proceso inclusivo para sordos y discapacidades auditivas: una búsqueda en revision}

Kaio Germano Sousa da Silva

ORCID: https://orcid.org/0000-0003-4236-6230

Faculdade do Vale Elvira Dayrell, Brasil

E-mail: kaiogsds@hotmail.com

Franklane Silva Cantanhede

ORCID: https://orcid.org/0000-0001-5115-4817

Centro Universitário de Ciências e Tecnologia do Maranhão, Brasil

E-mail: cfranklane@gmail.com

Solange Gonçalves Nunes de Sousa

ORCID: https://orcid.org/0000-0003-4327-9323

Universidade Estadual do Maranhão, Brasil

E-mail: Solange.nunes_@hotmail.com

Conceição de Maria Machado Costa Primo

ORCID: https://orcid.org/0000-0002-0837-2314

Universidade Estadual do Piauí, Brasil

E-mail: mara.con6ao@ hotmail.com

Adailza Lacerda e Silva

ORCID: https://orcid.org/0000-0001-8662-118X Centro Universitário Leonardo Da Vinci, Brasil

E-mail: lacerdaadailza1@gmail.com

Ana Larissa Cardoso Silva Rocha

ORCID: https://orcid.org/0000-0002-3014-1029

Instituto de Ensino Superior Múltiplo, Brasil

E-mail: analarissacss@ hotmail.com

Maria Conceição dos Santos

ORCID: https://orcid.org/0000-0002-0111-6916

Faculdade de Ensino Dom Bosco, Brasil

E-mail: ceicaapae1408@gmail.com

Ana Cristina Lima Costa

ORCID: https://orcid.org/0000-0003-3871-0668

Universidade Estadual do Maranhão, Brasil

E-mail: bellacris_gata87@hotmail.com

Flavia Gomes de Oliveira

ORCID: https://orcid.org/0000-0003-2652-2176

Escola Nacional de Saúde Pública Sergio Arouca, Brasil

E-mail: flaviagomesofc@gmail.com

George do Carmo Leão

ORCID: https://orcid.org/0000-0001-9106-1500

Centro Universitário de Ciências e Tecnologia do Maranhão, Brasil

E-mail: georgeleao13@gmail.com

Hidra Santana e Silva Morais

ORCID: https://orcid.org/0000-0002-0811-5422

Universidade Anhanguera, Brasil

E-mail: hidra.s.morais@gmail.com

Luana Pereira Ibiapina Coêlho

ORCID: https://orcid.org/0000-0002-2054-959X

Universidade Estadual do Maranhão, Brasil

E-mail: luana_ibiapina@ hotmail.com

Maria de Jesus Áraújo Guimaraes ORCID: https://orcid.org/0000-0002-7605-1782 Centro Universitário Leonardo Da Vinci, Brasil

E-mail: guimaraesmariaaraujo@gmail.com

Orquideia Pereira do Carmo Silva

ORCID: https://orcid.org/0000-0002-6248-3621

Universidade Federal do Piauí, Brasil E-mail: orkflor@gmail.com

Mogeane Pereira Lopes Antunes ORCID: https://orcid.org/0000-0002-5524-6265 Centro Universitário Maurício de Nassau, Brasil E-mail: mogeanem12@gmail.com 
Francioneide Patrícia de Sousa

ORCID: https://orcid.org/0000-0002-1482-0013

Faculdade Adelmar Rosado, Brasil

E-mail: francioneidepatricia@gmail.com

Rafael Roberval Teixeira Silva

ORCID: https://orcid.org/0000-0001-5683-5769

Centro Universitário Maurício de Nassau, Brasil

E-mail: rafael.apolonioteixeira@gmail.com

Rafael Fernandes de Melo

ORCID: https://orcid.org/0000-0002-9691-4362

Centro Universitário de Ciências e Tecnologia do Maranhão, Brasil

E-mail: rafaellffernandes1001@gmail.com

Raquel Chiara Teixeira Gonçalves de Jesus Nogueira

ORCID: https://orcid.org/0000-0002-3909-5997

Faculdade de Ensino Superior Dom Bosco, Brasil

E-mail: raquelchiara16@gmail.com

Rosa da Silva Magalhães

ORCID: https://orcid.org/0000-0002-7529-9284

Faculdade de Ensino Superior Dom Bosco, Brasil

E-mail: rosa_magal_silva@hotmail.com

Rosinei Nascimento Ferreira

ORCID: https://orcid.org/0000-0003-2732-7778 Instituição de Gestão Educacional Signorelli, Brasil

E-mail: rosineifff2@hotmail.com

Saleia Soares Leitão Silva

ORCID: https://orcid.org/0000-0001-8627-3680 Universidade Federal do Piauí, Brasil

E-mail: saleiasoares@hotmail.com

Bruna Rafaelle Pereira Ibiapina Coêlho

ORCID: https://orcid.org/0000-0002-3122-4803

Escola de Saúde Pública do Ceará, Brasil E-mail: bruna.ibiapina@hotmail.com

Maria Edileuza Silva dos Santos

ORCID: https://orcid.org/0000-0002-7457-8310

Universidade Estadual do Maranhão, Brasil E-mail: mariedileuza022@gmail.com

Ana Savia Constâncio da Silva

ORCID: https://orcid.org/0000-0002-5062-6680

Universidade Estadual do Maranhão, Brasil

E-mail: anasavia45@gmail.com

Larissa Lima Marques Coimbra

ORCID: https://orcid.org/0000-0001-7827-9871 Faculdade Laboro, Brasil

E-mail: coimbralarissa@gmail.com

Elisama Silva Barros dos Santos

ORCID: https://orcid.org/0000-0002-7424-5735

Universidade Anhanguera, Brasil

E-mail: elisama1975@hotmail.com

Jacinta Chaves dos Santos

ORCID: https://orcid.org/0000-0003-0484-2101

Universidade Estadual do Maranhão, Brasil

E-mail: dinychaves123@gmail.com

\section{Resumo}

Trata-se de uma revisão de literatura de cunho narrativa, baseada em uma ampla discussão da produção temáticocientífica. O mesmo consistiu-se numa pesquisa qualitativa, utilizando uma investigação bibliográfica de caráter narrativo realizada através de consulta em bases de dados online de pesquisa: Scielo, ERIC e Google acadêmico. Em uma análise das conquistas dentro do âmbito da inclusão no que se refere a garantia de direitos para sujeitos Surdos ou com deficiência auditiva, as leis do Brasil têm assegurado a esses indivíduos como cidadãos e membros civis desta sociedade o total direto de usufruir destes, seja elas no âmbito educacional ou em seu convívio social. Trazendo para as políticas, infelizmente, a política educacional de surdos no Brasil, que visam garantir que alunos surdos concluam a educação regular em situação igualitária com alunos surdos e falantes do Português, não funcionam inteiramente na prática. A necessidade de conhecer a dinâmica da libras nas diferentes modalidades de ensino é de suma importância para se montar estratégias de combate à não alfabetização dos alunos com surdez, preconceito e criação de meios para melhorar a educação e a qualidade de vida da pessoa surda.

Palavras-chave: Surdez; Perda auditiva; Inclusão escolar. 


\begin{abstract}
This is a literature review of a narrative nature, based on a broad discussion of thematic-scientific production. The same consisted of a qualitative research, using a bibliographic investigation of narrative character carried out through consultation in online research databases: Scielo, ERIC and academic Google. In an analysis of the achievements within the scope of inclusion regarding the guarantee of rights for Deaf or hearing impaired subjects, the laws of Brazil have ensured these individuals, as citizens and civil members of this society, the total right to enjoy them, either them in the educational sphere or in their social life. Bringing to policy, unfortunately, the educational policy for the deaf in Brazil, which aims to ensure that deaf students complete regular education on an equal footing with deaf and Portuguese-speaking students, does not fully work in practice. The need to know the dynamics of Libras in different teaching modalities is of paramount importance to mount strategies to combat the non-literacy of students with deafness, prejudice and the creation of means to improve the education and quality of life of deaf people.
\end{abstract}

Keywords: Deafness; Hearing loss; Mainstreaming, Education.

\title{
Resumen
}

Se trata de una revisión bibliográfica de carácter narrativo, basada en una amplia discusión de la producción temáticocientífica. El mismo consistió en una investigación cualitativa, utilizando una investigación bibliográfica de carácter narrativo realizada mediante consulta en bases de datos de investigación online: Scielo, ERIC y Google académico. En un análisis de los logros en el ámbito de la inclusión en materia de garantía de los derechos de las personas sordas o con discapacidad auditiva, las leyes de Brasil han asegurado a estas personas, como ciudadanos y miembros civiles de esta sociedad, el derecho total a disfrutarlos, ya sea en el ámbito educativo o en su vida social. Llevar a la política, lamentablemente, la política educativa para sordos en Brasil, que tiene como objetivo garantizar que los estudiantes sordos completen la educación regular en pie de igualdad con los estudiantes sordos y de habla portuguesa, no funciona plenamente en la práctica. La necesidad de conocer la dinámica de Libras en las diferentes modalidades de enseñanza es de suma importancia para montar estrategias que combatan la no alfabetización de los estudiantes con sordera, los prejuicios y la creación de medios para mejorar la educación y la calidad de vida de las personas sordas.

Palabras clave: Sordera; Pérdida auditiva; Integración escolar.

\section{Introdução}

O estudo vem apresentar como acontece a elaboração da inclusão dos alunos surdos ou caracterizados como deficientes auditivos, além de mostrar a importância da Libras para o surdo e para o deficiente que a adota como língua mãe ou L1 (Primeira Língua), em consonância na busca de entender o processo inclusivo da Libras e sua prática didática.

Nesta perspectiva, dentro do contexto do âmbito social do surdo sua comunidade entende que qualquer indivíduo que possui sua audição ou oralidade comprometida tem como garantia em legislação a escolha da Libras como forma de comunicação ou L1, os deficientes auditivos que possuem perdas no trato auditivo, desde a moderada até a severa, podem ter como aquisição a Língua de Sinais como ferramenta de interação linguística (Farias, Oliveira, \& Cenci, 2020).

Com isso a Língua Brasileira de Sinais é de suma importância para a comunicação dos surdos e sujeitos com deficiência auditiva como também a segunda língua oficial em todo território brasileiro (Viana \& Lebedeff, 2021). Dentro do contexto educacional, é notório o grande avanço da inserção da língua de sinais para todos os âmbitos, com isso, é evidente um elevado índice de avanços para surdos, principalmente, no ensino e aquisição da Libras em instituições de ensino onde sua elaboração acontece de forma eficiente.

No pensamento de Farias, Oliveira e Cenci (2020) o mesmo fala que inclusão é garantia de direitos, afim de proporcionar qualidade de vida de indivíduos com deficiência auditiva ou surdos, a nível educacional a Libras tem como objetivo central reparar as necessidades deste público surdo de forma individual e coletiva em sua interação, tornando-a mais acessível em todos âmbitos em que estes indivíduos estão inseridos.

A realização deste estudo, trabalhou-se em responder o seguinte questionamento: "como se dá a dinamização da inclusão dos Surdos e deficientes auditivos dentro do contexto escolar?". Para isso, este trabalho tem como objetivo caracterizar através de uma investigação da literatura como ocorre a elaboração da inclusão de surdos e deficientes auditivos, dentro do âmbito educacional.

A importância na escolha do tema surgiu pela curiosidade em entender como ocorre o processo inclusivo do surdo e 
deficiente auditivo nas escolas e a determinar a importância da Libras como L1, como facilitadora do desenvolvimento do ensino e aprendizagem, e como forma de garantir direitos e auxiliar no melhoramento do processo de comunicação do surdo, deficientes e ouvintes.

\section{Metodologia}

Trata-se de uma revisão de literatura de cunho narrativa, baseada em uma ampla discussão da produção temáticocientífica. $\mathrm{O}$ mesmo consistiu-se numa pesquisa qualitativa, utilizando uma investigação bibliográfica de caráter narrativo realizada através de consulta em bases de dados online de pesquisa: Scielo (Scientific Eletronic Library OnLine), ERIC (Education Resources Information Center) e Google acadêmico. A pesquisa foi realizada no ano de 2021, com artigos que se encaixavam no recorte temporal de 2014 a 2021, entretanto alguns artigos fora do recorte temporal foram utilizados por conta da temática e da grande relevância.

Foram utilizados os seguintes descritores e suas consonâncias nas Línguas Portuguesa, Espanhola e Inglesa: "Surdo 1", "Deficiente Auditivo 2", "Inclusão Escolar 3". Vocábulos com grau de semelhança foram usados em outras bases de dados. Seguindo o trajeto metodológico, foram identificados 15 artigos de acordo com esses termos usados, sendo 5 artigos oriundos do Google acadêmico, 2 oriundos da Scielo e 8 oriundos da ERIC.

Como critérios de inclusão utilizou-se estudos disponíveis em sua totalidade, nos idiomas Português, Espanhol e Inglês. Foram excluídos capítulos de livros, resumos, cartas ao editor, comentários, casos em séries e textos incompletos, trabalhos que não se adequavam com os objetivos e ao tema proposto em conjunto com os descritores "1", "2", “3".

\section{Resultados e Discussão}

\section{História da educação dos surdos}

A história da Libras no Brasil se inicia devido a Dom Pedro II ter interesse de querer a implementação da educação dos Surdos, isso acontece em decorrência do monarca ter um neto com deficiência auditiva, filho da princesa Isabel, assim, Dom Pedro II desejava muito que a criança fosse alfabetizada. Desta forma viu-se a necessidade de convidar o professor e um dos precursores da Libras na França, o francês Hernest Huet para dar início ao processo inclusivo da Língua Brasileira de Sinais (Bahan, 2018).

Ao chegar ao Brasil, um ensino com muitas problemáticas foi o que o professor encontrou, o mesmo viu a necessidade de fundar uma instituição, com finalidade de tornar o ensino com menos mazelas, teve a ideia de pedir ao imperador uma sala, e foi 1857, mais especificamente no mês de setembro no dia 26, fundou o Instituto dos Surdos-Mudos, chamado assim na época, no estado do Rio de Janeiro (Farias, Oliveira, \& Cenci, 2020).

Em 1923 foi fundada uma escola de cunho privado no estado de São Paulo. só que foi destinada somente para o público feminino, escola essa denominada, de Instituto Santa Terezinha. Em 1957 foi fundada uma escola em Vitória, Espírito Santo, para atender a demanda e alfabetizar as pessoas com surdez. (Cosson, 2016).

Atualmente, existem arquivos de escolas municipais para atender os surdos, como a Hellen Keller uma escola em Caxias do Sul e a Anne Sullivan na bela São Caetano do Sul no estado de São Paulo. Escolas essas que tem como objetivo a Libras como aquisição em forma de inclusão e disciplina em seu currículo com finalidade de melhorar o aprendizado (Felipe, 2018).

\section{Leis e Direitos do Surdo e Deficientes Auditivos}

Em uma análise das conquistas dentro do âmbito da inclusão no que se refere a garantia de direitos para sujeitos Surdos ou com deficiência auditiva, as leis do Brasil têm assegurado a esses indivíduos como cidadãos e membros civis desta 
sociedade o total direto de usufruir destes, seja elas no âmbito educacional ou em seu convívio social (Honora, 2019).

A lei $n^{\circ}$ 9.394, de 20 de dezembro de 1996 tem como finalidade garantir a inclusão de cuidadores em escola em auxílio aos alunos com deficiência, desta forma garantindo que estes alunos não tenham obstáculos em seu processo de ensino e aprendizagem, entretanto tais profissionais devem passar por uma série de treinamento e formação continuada (Lei n ${ }^{\circ} 9.394$, 1996).

Trazendo para a perspectiva de aluno surdo ou com surdez, no Brasil existem leis que garantem uma igualdade parcial, em facilitar seu processo de ensino e convívio social, um exemplo disso é a determinação de $\mathrm{n}^{\circ} 5.626$, de 22 de dezembro de 2005, no qual esse decreto nos seus aspectos legais vem garantir tanto para o deficiente auditivo como para o surdo, amparo nos âmbitos educacional, da saúde e social. Tal lei garante ainda a presença de um intérprete de Libras em salas de aulas, para auxiliar no processo de formação e alfabetização do aluno surdo ou deficiente auditivo, já que a alfabetização na Libras se dá com presença de um intérprete (Decreto nº 5.626, 2005).

$\mathrm{O}$ decreto ainda garante que o intérprete e professor devam ser capacitados e ter uma formação continuada semestralmente, para proporcionar um melhor aprendizado para estes alunos, e desta forma tentar minimizar os traumas e capacitar estas pessoas que convivem com alguma deficiência específica (Klein \& Lunardi, 2018).

Historicamente, a Língua Brasileira de Sinais (LIBRAS), dá o direto ao acesso de pessoas com alguma deficiência no Ensino Regular, respaldado pela Constituição de 1988 e pela LDB de 1996, nesta perspectiva não se pode excluir nenhuma pessoa por ser diferente. A legislação vigente e presente caracteriza a oferta de suporte adequado ao atendimento de cunho especializado às pessoas com deficiência.

No decreto $n^{\circ} 5.626$, de 22 de dezembro de 2005, mais especificamente no artigo 22, as instituições e centros educacionais, que são responsáveis pela gestão da Educação Básica, tem seus princípios obrigatórios a inclusão dos surdos e deficientes auditivos, de forma coordenada e contínua. É de suma importância o corpo jurídico assegurar de forma clara os direitos do surdo, a fim de melhorar o processo de desenvolvimento cognitivo (Decreto $\mathrm{n}^{\circ} 5.626,2005$ ).

No contexto da inclusão, para os alunos com deficiência auditiva, os mesmos têm necessidade de adquirir aprendizagem da Libras reconhecida pela Lei Federal no 10.436/02, que assegura que essa língua é o principal meio de comunicação dos surdos, por sua vez, isso fortalece as conquistas e fortalece os movimentos de militância dos surdos (Quadros, 2014). Essa lei é um recurso legal que garante e confirma a Libras como umas das línguas usadas pela comunidade surda no Brasil.

\section{Relação do surdo e deficiente auditivo durante a aula}

Trabalhar em sala de aula diversificadas cultural e linguisticamente pode representar desafios para os pesquisadores monolíngues que desejam obter perspectivas para as crianças. Quando existem limites linguísticos, uma abordagem recomendada é trabalhar com um intérprete, no entanto, pouco é relatado sobre a eficácia desta abordagem (Farias, Oliveira, \& Cenci, 2020).

Por exemplo, como a presença do intérprete facilita a conversação e quais condições interacionais ajudam a fluir as conversas? As descobertas mostram que, pode melhorar a representação e a participação em pesquisas para crianças de diversas comunidades. Desta forma o processo de alfabetização dos alunos surdos e de alunos com alguma deficiência auditiva é algo que vem sendo discutido em inúmeras reuniões, encontros, congressos e escolas para que o mesmo possa ter uma funcionalidade de inclusão para os estudantes com surdez (Silva et al., 2021). Tais discussões, podem promover uma expansão do assunto, com intuito de se fomentar estratégias afim de melhorar a alfabetização desse indivíduo, isso não depende somente da escola e famílias, mas sim também da pessoa surda ou deficiente aceitar e ter acessos aos parâmetros que são pertinentes a ele, com isso o processo de alfabetização deve ter um trabalho em conjunto com todos os âmbitos que o aluno vive, de um 
modo facilitador deste processo (La Taille, 2019).

Deste modo para que o processo de alfabetizar uma criança com surdez seja eficaz, é necessário primeiramente alfabetizá-lo em sua língua para depois adquirir outro idioma. Isso abrange todos os aspectos: educacional, social, familiar e profissional, na qual se tornam um dos maiores desafios abordados na educação inclusiva (Novaes, 2018).

Um aluno com problemas auditivos pode interagir e participar juntamente com os demais educandos nas atividades da sala de aula regular, fazendo uso dos dois idiomas principais do Brasil, a LIBRAS (como L1) e o Português escrito (como L2). Desde que o educador possa inclui-lo em todas as atividades de ensino aprendizagem, sem haver separação de ouvintes e surdos, possibilitando aos alunos a percepção em distinguir a relação da língua falada e escrita como fonte de interação e comunicação entre as pessoas (Dantas, Braga, \& Fernande, 2018).

Na perspectiva do bilinguismo inaugura-se um novo debate na área da surdez, ele defende a primazia da Língua de Sinais sobre a Língua Portuguesa (Santana \& Festa, 2014). O bilinguismo é uma proposta de ensino usada por escolas que se propõe tornar acessível às crianças surdas duas línguas no contexto escolar. Respeitando-se a cultura própria da comunidade surda, fazendo com que o surdo se reconheça como parte desta, mas não isolando estes cultural e socialmente, permitindo o acesso à cultura da comunidade ouvinte.

$\mathrm{Na}$ contemporaneidade políticas inclusivas garantem a educação especial em escolas regulares, fornecendo instrumentos necessários e adequando o ambiente, bem como o corpo docente, para melhor atender a todos. Em relação aos alunos surdos pode-se afirmar que o maior aliado para a que a inclusão para acontecer em sua totalidade é a presença de interprete (Carvalho, Duarte, Menezes, \& Souza, 2019). Sendo assim, as políticas têm uma finalidade de colocar estratégias no ponto de alfabetização do aluno com deficiência ou surdez, cabe a escola e a família estarem atentos a esse processo para que o mesmo seja satisfatório na vida e no ensino e desenvolvimento, e quando estes pilares não têm interesse em permitir o processo o aluno tende a desanimar, atrasando-se e perdendo toda a sua vida escolar (Luz, 2016).

No que se refere aos espaços inclusivos, eles têm o objetivo de diminuir a discriminação com pessoas que possuem limitações, as escolas devem oferecer apoio para que esse aluno se sinta seguro no seu espaço de ensino, nos espaços educativos devem existir profissionais que possuem formação na área especifica da deficiência destes alunos, para os ambientes tornem-se inclusivos e respeitosos com as debilitações destes indivíduos (Schlemper, 2016). Deve-se investir em formação continuada para todos os profissionais, um curso para os colegas, apoio pedagógico para os pais, informativos para auxiliar a locomoção deste e por fim intérpretes e cuidadores a fim de complementar a vida dos alunos (Silva \& Córdula, 2018).

No país a realidade é bem diferente, o intérprete ainda não tem o apoio devido no âmbito escolar para lidar com os desafios encontrados com o discente surdo. Este não deve trabalhar sozinho, precisa-se primeiramente do apoio da família e de toda comunidade escolar. Há todo um trabalho que é realizado com os alunos surdos e o intérprete é quem tem a função de ligar todos os pontos e utilizar o conhecimento que o aluno surdo adquiriu em sua língua natural e em Língua Portuguesa, para que ele entenda os conteúdos que estão sendo ministrados (Farias, Oliveira, \& Cenci, 2020).

Embora muitos pensem que o oralismo é uma forma eficaz e que pode trazer algum benefício ou um avanço para o surdo, esse método, por não possibilitar que o surdo desenvolva a linguagem de forma natural, não é totalmente adequado. A linguagem do oralismo foi e continuará sendo uma experiência pouco atrativa para a aquisição da língua e avanços da comunidade surda (Quadros, 1997). Nestes moldes, a proposta oralista simplesmente desconsidera as questões relacionadas à cultura e à sociedade surda. Sem poder se expressar da maneira natural, os surdos sentem-se apátridas, deslocados e em constante conflito com a realidade que os circunda.

Sintetizando, de acordo Dalcin (2019) a Língua de Sinais não está voltada somente para dialogação e comunicação, é uma junção de saberes culturais, uma simbologia na construção da identidade destes sujeitos, dando ênfase na história e 
valores e costumes dos mesmos. A formação de identidade ou descobrimento da mesma vem como ferramenta de valorização da cultura surda, e essas descobertas, despertam o indivíduo a gostar e se sentir capaz suficiente para buscar seu empoderamento, mesmo sofrendo alguns obstáculos na sua inclusão.

A escola vem para ajudar na superação destes obstáculos. Portanto o educador como profissional mediador de conhecimentos e transmissor de saberes, valores morais e ideais, deve dispor de uma forma de ensino que possa transmitir confiança para os alunos, fazendo com que estes participem do processo educacional independente de qualquer limitação que seja, sem nenhuma forma de preconceito ou discriminação no meio educacional que está inserido (Murgo, Alves, \& Francisco, 2016). Sendo está a principal tarefa do professor, promover uma sensibilização entre os educandos da turma a respeito dos colegas deficientes para que os estudantes ditos normais possam se relacionar com os colegas de forma respeitosa e acolhedora, sendo o ensino produzido de maneira democrática em sala de aula (Muller \& Kist, 2018).

Nenhum método único ou combinado pode ensinar com sucesso todas as crianças a ler. Portanto, os professores devem ter um conhecimento profundo destas metodologias de ensino de leitura múltipla e das crianças de quem cuidam, para que possam criar um equilíbrio adequado de ações de acordo com as necessidades de cada aluno (Machado \& Prestes, 2017). Nessa perspectiva, discutir de forma geral, o convívio social da pessoa surda, no intuito de anseio da pesquisa central reparar as necessidades deste público surdo de forma individual e coletivo em sua interação, tornando-a mais acessível.

\section{Relacionamento dos surdos e deficiente auditivo na comunidade escolar}

A deficiência auditiva tem a presença de alguns tipos principais de problemas relacionados ao aparelho auditivo, como a deficiência em transmitir ou condução e também com problemas na síntese da neurossensorial. A surdez de transmissão é caracterizada pela lesão no ouvido externo ou médio, causando parcialmente a perda da audição.

Ao contrário das crianças com audição normal, as surdas por vezes não conseguem dominar a sua língua, por isso que as escolas devem estar atentas à criação de um ambiente onde primeiro aprendam a língua gestual e depois aprendam o português. Para que se construa uma identidade e conquiste seu espaço, inserindo-se na sociedade, a pessoa surda precisa ter contato com outras pessoas surdas. A cultura surda é a identidade cultural dos surdos, pois inseridos nesse meio, eles se sentem seguros e acolhidos, sendo possível a comunicação semelhante a eles (Delgado \& Cavalcante, 2014).

A aprendizagem é realizada por meio de um intérprete, que traduz o conteúdo transmitido pelo professor, mas é importante observar que só porque um intérprete está presente na sala de aula não significa que ele possa garantir a inclusão, isso requer a ação de dois profissionais (Santana \& Festa, 2014).

Trazendo para as políticas, infelizmente, a política educacional de surdos no Brasil, que visam garantir que alunos surdos concluam a educação regular em situação igualitária com alunos surdos e falantes do Português, não funcionam inteiramente na prática. Ainda se tem relatos da não aceitação dos profissionais da educação que desconhecem seu papel de atuação no ensino do aluno surdo.

A libras vem conquistando seu espaço no que se refere a inclusão. O desafio atual é transformar a escola de todos em uma instituição igualitária, atualizar suas práticas educacionais para tentar atender à realidade dos desafios da sociedade e formar um cidadão comprometido (Damázio, 2017). Como várias línguas de sinais e línguas faladas, a libras possui todos os níveis linguísticos da fonética, morfologia, sintaxe, semântica e pragmática, possui estrutura gramatical própria e é adequada para transmissão de informação e ensino. A gramática das libras é composta por elementos constituintes, palavras ou itens do vocabulário (Farias, Oliveira, \& Cenci, 2020).

Dentro do contexto da inclusão do aluno surdo, a mesma deve acontecer em todas a modalidades de ensino que vai da educação infantil chegando até o nível superior, dando garantias, na utilização de recursos que venham facilitar e auxiliar na superação de barreiras no processo da oferta educacional e que os mesmos possam usufruir seus direitos dentro do contexto 
escolar, contribuindo para exercício de sua cidadania, seguindo os princípios constitucionais do Brasil (Lopes \& Veiga-Neto, 2020).

Sabe-se que a política da segregação de pessoa com deficiência ocorreu desde o momento da criação das escolas especiais, pois os que apresentavam certo tipo de incapacidade ou limitação, deveriam ficar em escola separada. Esse método tornava nula a oportunidade de se alcançar uma Educação Inclusiva propriamente dita (Silva \& Córdula, 2018). A necessidade de conhecer a dinâmica comportamental do surdo nos diferentes âmbitos de convívio social, é de suma importância para se montar estratégias de combate à exclusão total destes indivíduos.

A pessoa surda precisa de um espaço que contribua para a construção de uma identidade e do fortalecimento de sua cultura. Isso se dá através de contato com pessoas surdas, podendo-se adquirir um vocabulário mais extenso que serve para reafirmar sua identidade e através do contato com ouvintes para que seja possível sua inserção no contexto social.

\section{A inclusão das libras na vida do surdo e deficiente auditivo}

É de suma importância um intérprete de Libras em sala de aula como ferramenta de inclusão e auxílio de ensino do surdo, pois o mesmo capacitado na intermediação da alfabetização tem sua parte essencial no processo de ensino e alfabetização. O interprete vem como forma de garantir a lei e acessibilidade as pessoas com deficiência auditiva, com isso ajuda professores em sala regulares no processo sociabilidade dos mesmos.

Segundo Dantas, Braga e Fernande (2018) as metodologias de ensino estão se tornando muito tradicionais e não acompanhando os avanços da tecnologia no âmbito educacional. Com isso, Hirata (2018) em seu estudo original abre uma discussão para que exista mais capacitação dos profissionais e não profissionais envolvidos na vida do surdo, a autora traz uma reflexão da grande necessidade do estado investir na formação de profissionais, instrutor, interprete e tradutor, com o principal objetivo de proporcionar um ensino adequado aos surdos e deficientes auditivos oferecendo um processo inclusivo real.

É preciso metodologias modernas e estratégias de ação afim de melhorar o trabalho destes profissionais para que resultados possam ser alcançados em todas as modalidades de ensino, e que o aluno surdo possa compreender e participar de sua vida educacional, onde possa se tornar crítico e fundamentar teorias e ao mesmo tempo seja atuante em seu crescimento social e participação na implementação dos seus direitos básicos (Farias, Oliveira, \& Cenci, 2020).

Intérpretes educacionais em áreas específicas precisam realizar a formação necessária ao nível em que atuarão para aprimorar as diferentes formas de ensino, os cursos de formação diferenciados e, por fim, a urgência de políticas públicas voltadas para as características de atuação para atuar em ambiente educacional Intérprete (Silva \& Córdula, 2018). Entretanto, pode-se notar que deve existir uma nova avaliação de currículos, afim de melhorar a oferta da inclusão, no caso deste estudo a Inclusão da libra que não deve ser ofertada somente na escola que possui alunos com surdez, e sim em todas as escolas deve existir a Libras como disciplina presente em todas as modalidades de ensino, já que a mesma é segunda língua oficial do país (Muller \& Kist, 2018).

\section{Conceito de inclusão}

Nos últimos anos os princípios que nortearam a educação inclusiva surgiram durante documentos internacionais produzidos em congressos internacionais, onde os mesmos serviram e servem de base na educação, neste sentido a educação deve ser direitos para todos, não somente como constituintes nacional, mas sim universal (Unesco, 1994).

Nesta perspectiva trazendo a inclusão para o indivíduo com deficiência auditiva, onde o mesmo durante séculos sofreu por diversos povos, quando não eram mortos eram obrigados a falarem, sem sucesso de tais práticas, as pessoas com comorbidades auditivas foram retirados das escolas e marginalizados culturalmente, e isso se deu ao congresso de Milão ocorrido no ano de 1880 onde tal evento declarou que a educação na modalidade gestual era inferior ao oralismo. Mas a cultura 
surda, que também inclui pessoas com baixa audição, não deixou abater-se, graças a declaração de Salamanca que retificou a declaração de Milão, assumindo no ano de 1994 o compromisso de implementar e de resolver uma solução inclusiva não somente para os surdos, mas qualquer indivíduo com deficiência (Unesco, 1994).

Ainda em um contexto histórico, o processo inclusivo na educação se define de acordo com diversas literaturas, sendo denominado como um movimento de cunho educacional, social e político, que tem como princípio garantir e defender os direitos dos indivíduos com deficiência ou não, que vem fomentar que todos os indivíduos participem de forma consciente e responsável na sociedade a qual fazem parte, para que tais indivíduos sejam aceitos e respeitados no que os diferenciam dos outros (Damázio, 2017).

Na perspectiva do real objetivo da inclusão no âmbito educacional, a inclusão ajudará o aluno a aprimorar a competência que lhe permite a exceção dos seus direitos de cidadão, através de qualidade educacional. A inclusão vem proporcionar e nortear a escola, família e aluno, para que o aluno cresça capaz de tomar suas decisões. Entretanto, a inclusão se torna mais difícil quando a escola ou até mesmo a família não trabalham juntos para garantir o real conceito da inclusão, que é incluir os indivíduos em seus direitos

Deste modo, já existe um consenso de que qualquer pessoa que tem em sua vivencias a exclusão educacional, tem como resultado deste problemática menos oportunidades nos vários âmbitos da sociedade assim como o aumento da probabilidade de vivenciar experiências e situações de discriminação, como também problemas financeiros na vida de adulto (Farias, Oliveira, \& Cenci, 2020).

A inclusão tem como proposta mudar a resposta educativa, com principal intuito de fornecer uma educação de qualidade e igualdade a todos os alunos, a mesma conceituada em parágrafo supracitado acima tem sido vista como meio de exclusão educacional, pois o processo inclusivo não acontece em outros meios. Sabe-se que só a legislação não garante a inclusão educacional, já que no decorrer da integração, existem algumas barreiras que dificultam o processo de uma educação igualitária a todos. Assim, a inclusão vem trazer sua importância no seu aspecto social e emocional e garantia de direitos, pois a mesma é uma forma de proporcionar aquilo que é necessário ao convívio do indivíduo que possui necessidades ou não, afim de proporcionar qualidade de vida, ela também vem se tornar uma ferramenta de grande valia no processo de ensino e aprendizagem tanto no aspecto alfabetizador como psicomotor (Damázio, 2017).

No contexto do surdo e deficiente auditivo, é importante lutar por mais direitos em prol de melhorias, na área da educação e áreas afins. Imensamente importante, esta luta se embasa nesse sentido de melhorar o sistema, como forma de garantir qualidade de vida e uma valorização da cultura surda, nada está adaptado só está se garantido o que já é previsto em lei. Há muito que ainda deve ser feito, como libras nos currículos de todos, libras na saúde, segurança e ter mais representatividade no sentido cultural.

Com isso, o conceito de inclusão vai variar de acordo com a individualidade de cada indivíduo, mas igual e universal a todos. O processo inclusivo previsto em lei não deve ser visto somente como garantia de direitos e sim como prática em um cotidiano escolar para que a mesma seja aproveitada no contexto familiar, social e político.

\section{Conclusão}

Essa pesquisa teve como objetivo responder aos questionamentos supracitados no decorrer da construção desse trabalho, tendo como base a dinamização da inclusão do deficiente auditivo e surdo no âmbito educacional. Partindo dos dados obtidos constatou-se que a inclusão dos surdos e deficientes auditivos, nas escolas, englobando alunos e profissionais, é uma área que precisa ter maior visibilidade nas formas de como esse trabalho deve acontecer.

A inclusão das libras na vida educacional do aluno surdo e alunos com limitação auditiva, se mostra ser importante quando o mesmo tem acesso a todos os níveis de ensino de forma gratuita, onde o mesmo consegue ter garantias de direitos, 
como interprete em sala, alfabetização em duas línguas, facilitação de comunicação com indivíduos sem conhecimento em libras e entre outras.

Com isso os objetivos do presente trabalho foram alcançados, onde se discutiu a dinâmica da inclusão dos surdos e deficiente auditivo no âmbito educacional, se falou da dinâmica da libras em cada nível, de forma individual e coletiva, e ações e novas metodologias, a importância da inclusão social fez parte do corpo deste trabalho deixando de forma clara e objetivo a sua real função na mudança de um sistema que se preocupa somente em garantir a lei, se discutiu também as estratégias para o profissionais da educação e até mesmo para surdos e ouvintes, afim de melhorar a convivência e estratégias de cunho global que melhore a educação de surdo a níveis nacionais.

Essa discussão pode auxiliar os profissionais e estudantes da inclusão, que buscam aprender o contexto educacional e social no qual estão inseridos, pois, ao relacionar suas experiências com a teoria proporcionam o processo inclusivo real em sua totalidade. É de suma importância conhecer a dinamização da inclusão dos alunos com surdez nas escolas da rede pública, para se ter uma melhor compreensão em explorar e elaborar ações de melhorar esse âmbito.

A necessidade de conhecer a dinâmica da libras nas diferentes modalidades de ensino, é de suma importância para se montar estratégias de combate à não alfabetização dos alunos com surdez, preconceito e criação de meios para melhorar a educação e a qualidade de vida da pessoa surda, nesse caso é necessário compreender a libras e como essa dinâmica deve ser incluída para que o processo de ensino e aprendizado seja feito de forma adequada para se ter um melhor aproveitamento e resultados positivos.

Estudos de revisão são de suma importância para analisar a busca de respostas para determinados problemas, pois torna possível trabalhar com vários estudos sobre o tema discutido de forma categórica, sistemática e ordenada, permitindo formar discussões sobre objetivos alcançados pelos autores em várias linhas de tempo e comparar os mesmos, e se tais respostas se divergem ou se os mesmos resultados são iguais sem influência da linha de tempo.

\section{Referências}

Bahan, B. (2018). Face-to-Face Tradition in the American Deaf Community: Dynamics of the Teller, the Tale, and the Audience. In: Bauman, D., Rose, H., \& Nelson, J. Signing the Body Poetic: Essays on American Sign Language Literature (pp. 23-50). California: University of California Press.

Carvalho, L. O. R., Duarte, F. R., Menezes, A. H. N., \& Souza, T. E. S. (2019). Metodologia científica: teoria e aplicação na educação a distância. Petrolina: Fundação Universidade Federal do Vale do São Francisco.

Cosson, R. (2016). Letramento literário teoria e prática. Contexto.

Delgado, I. C., \& Cavalcante, M. C. B. (2014). A construção do aprendiz surdo na perspectiva da alfabetização e do letramento. In: Faria, M. B., \& Cavalcante, M. C. B. Desafios para uma nova escola: um olhar sobre o ensino-aprendizagem de surdos. Ed. Universitária da UFPB.

Damázio, M. F. M. (2017). Atendimento educacional especializado: Pessoa com surdez. SEESP/SEED/MEC.

Dantas, G. C., Braga, B. L. O., \& Fernande, A. P. C. S. (2018). O ensino de Libras na EJA: reflexão e proposições. Galoá Proceedings, 6(6), $100-114$.

Dalcin, G. (2019). Um estranho no ninho: um estudo psicanalítico sobre a constituição da subjetividade do sujeito surdo (Dissertação de Mestrado). Universidade Federal de Florianópolis, Florianópolis, SC, Brasil.

Decreto $n^{\circ}$ 5.626, de 22 de dezembro de 2005. Regulamenta a Lei n ${ }^{\circ} 10.436$, de 24 de abril de 2002, que dispõe sobre a Língua Brasileira de Sinais - Libras, e o art. 18 da Lei no 10.098, de 19 de dezembro de 2000. http://www.planalto.gov.br/ccivil_03/_ato2004-2006/2005/decreto/d5626.htm.

Farias, M. D., Oliveira, F. K., \& Cenci, A. (2020). Performance of the Brazilian Sign Language (Libras) interpreter translator in higher education: implications in the inclusive education discipline. Research, Society and Development, 9(1), 1-12.

Felipe, T. A. (2018). Introdução à Gramática da LIBRAS (Série Atualidades Pedagógicas). Secretaria de Educação Especial.

Honora, M. (2019). Livro Ilustrado de Lingua Brasileira de Sinais. Ciranda Cultural.

Klein, M., \& Lunardi, M. L. (2018). Surdez: um território de fronteiras. EDT: Educação Temática Digital, 7(2), 14-23.

La Taille, Y. L (2019). Piaget, Vygotsky, Wallon: teorias psicogenéticas em discussão. Summus.

Lei $n^{\circ}$ 9.394, de 20 de dezembro de 1996. Estabelece as diretrizes e bases da educação nacional. http://www.planalto.gov.br/ccivil_03/leis/19394.htm. 
Lopes, M. C., \& Veiga-Neto, A. (2020). Marcadores Culturais Surdos. In: Vieira-Machado, L. M. C., Lopes, M. C. (Org.). Educação de Surdos: políticas, língua de sinais, comunidade e cultura surda. EDUNISC.

Luz, R. D. (2016). Cenas Surdas: os surdos terão lugar no coração do mundo? Parábola.

Machado, F. M. A., Prestes, G. R. L. (2017). LIBRAS - Língua Brasileira de Sinais. Educs.

Muller, J. I., \& Kist, K. (2018). Língua Brasileira de Sinais e cultura surda: práticas inclusivas em um Instituto Federal. Línguatec, 5, 62-74.

Murgo, C. M., Alves, W. A., \& Francisco, M. V. (2016). A afetividade na relação professor-aluno: perspectivas de estudantes de Pedagogia. Rev. educ, 21(2), 211-220.

Novaes, E. C. (2018). Surdos: educação, direito e cidadania. Wak Editora.

Quadros, R. M. (1997). Educação de Surdos: efeitos de modalidade e práticas pedagógicas. In: Mendes, É. G., Almeida, M. A., \& Williams, L. C. A. (Orgs). Temas em Educação especial IV. EdUFSCar.

Quadros, R. M. (2014). Situando as diferenças implicadas na educação de surdos: inclusão/exclusão. Ponto de Vista, 5, 81-111.

Santana, L., \& Festa, P. S. (2014). A relação do intérprete de Libras é o aluno surdo: um estudo de caso. Revista Ensaios Pedagógicos, 7.

Schlemper, M. (2016). Traduções infantis para Libras: o conto como mediador de aquisição sinalar (Dissertação de Mestrado). Universidade Federal de Santa Catarina, Florianópolis, SC, Brasil.

Silva, A. P., \& Córdula, E. B. L. (2018). Desafios e possibilidades no processo de avaliação do(a) aluno(a) surdo(a). Revista Educação Pública, 17(7).

Silva, K. G. S., Santos, N. L. C., Silva, F. T. S., Sousa, S. G. N., Nascimento, C. D., Primo, C. M. M. C., \& Melo, K. C. (2021). Affectivity as a methodological practice in children's education: A narrative review. Research, Society and Development, 10(4).

Unesco. (1994). Declaração de Salamanca. Unesco.

Viana, J. M., \& Lebedeff, T. B. (2021). O sistema Shape Coding como ferramenta para a reflexão linguística em Língua Portuguesa para surdos. In: Silva, R. A. F., \& Hollosi, M. (Org.). Educação de surdos, linguagens e experiências. Editora Navegando. 